\title{
Spectroscopic Performance of Otoscopes during Otoscopic Exami- nation by LED Headlight
}

\author{
Mitsuhiro MATSUMOTO ${ }^{\dagger}$ \\ Kanagawa University, Department of Industrial Engineering and Management, Faculty of Engineering
}

Received January 21, 2021, Accepted May 17, 2021

Paper was originally published in Japanese in advance online publication of Journal of the Illuminating Engineering Institute of Japan, https://doi.org/10.2150/jieij.20000601.

\begin{abstract}
We evaluated the spectroscopic performance of an otoscope during otoscopic examinations using a headlight with an LED source. We used the mechanisms and the specifications of the objects measured with the otoscope and so on to evaluate the spectroscopic performance. Experimental equipment was built using the existing otoscope and headlight, and we demonstrated methods of measuring the spectral irradiance of the otoscope. We demonstrated methods of evaluating the spectroscopic performance using the spectral irradiance ratio and chromaticity by the measured spectral irradiance. We measured the spectral irradiance of the otoscope using the measuring methods. We found that the spectral irradiance distribution in the otoscope is greatly affected by the spectral distribution in the headlight source. We evaluated the spectroscopic performance of the otoscope using the evaluation methods. The spectroscopic performances of the reflected light onto the surface of, and the direct and reflected lights in, the otoscope differ and are affected by differences in shape, surface condition, length, and the diameter of the wide mouth. The spectroscopic performance of the direct and reflected lights in the otoscope is affected by differences in the diameter of a narrow mouth and the distance and angle between the otoscope and the headlight.
\end{abstract}

KEYWORDS: otoscope, headlight, otoscopic examination, LED, spectrum

\section{Introduction}

Otoscopic examinations investigate changes in color and morphology of the eardrum and ear canal inside the ear ${ }^{1)}$. With regards to changes in the color tone of the eardrum, a normal eardrum has a pearl-like grayishwhite translucent luster ${ }^{1}$. Pathological eardrums have reddening and hyperemia that appears reddish, appears opaque, and loses its luster, yellowish changes are transparent and have a starch syrup-like or paleyellow color, and blue-blackish changes appear blue or black ${ }^{1)}$. In otoscopic examinations, these changes in color are required to be accurately determined. Otoscopic examinations involve the use of a light source, head mirror, and otoscope ${ }^{2}$. The light from the light source is reflected by the head mirror and illuminates the inside of the ear through the otoscope ${ }^{1)}$. An incandescent light bulb is used as the light source ${ }^{3)}$. The head mirror is inconvenient because there are restrictions on the positional relationship between the light source, head mirror, and otoscope ${ }^{4}$. Therefore, headlights with a built-in light source are present instead of light sources and head mirror ${ }^{5}$. A light-emitting diode (LED) is used as the built-in light source ${ }^{6)}$. The incandescent light bulb, which is the light source, has different color tone and spectrum compared to the $\mathrm{LED}^{6,7)}$. The light that illuminates the inside of the ear includes direct light from the light source and light reflected on the surface of the otoscope ${ }^{8}$. The fraction of direct light and reflected light in the light that illuminates the inside of the ear depends on the shape, surface conditions, length, and wide-mouth/narrow-mouth diameters in the otoscope specifications as well as on the distance and angle between the otoscope and headlight ${ }^{8)}$. Otoscope surfaces include black, chromed matte, chromed gloss, and aluminized gloss, which have different spectral reflectances. The light that illuminates the inside of the ear is considered to have spectral irradiance that differs from the color tone and spectrum of the light source owing to differences in the specifications of the otoscope and positional relationship between the otoscope and headlight. The color tone inside the ear changes when the spectral irradiance is different. It has also been

\footnotetext{
${ }^{\dagger}$ Corresponding Author: Mitsuhiro Matsumotoｍ-matsumoto@kanagawa-u.ac.jp
} 


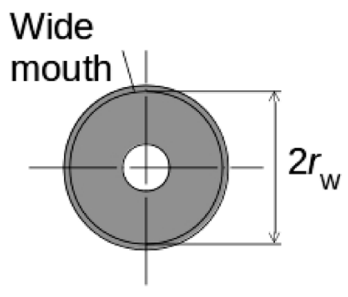

(a) Left side view

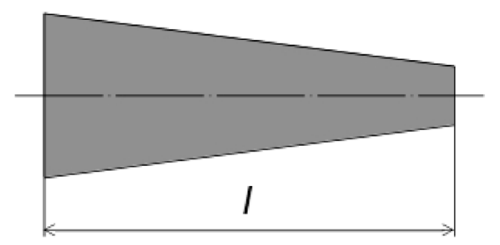

(b) Front view

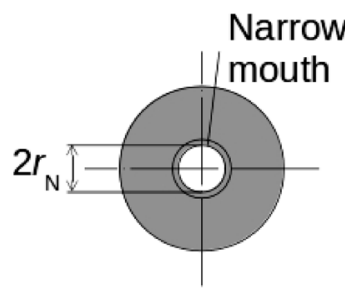

(c) Right side view

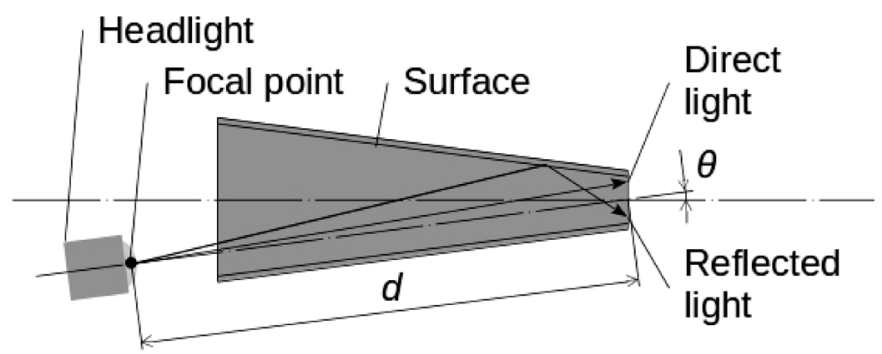

(d) Cross-section view

Figure 1 Mechanism of otoscope and relationship between otoscope and headlight.

indicated that doctors need to become accustomed to changes in color tone during examinations because they may be confused by the difference in color tone or feel uncomfortable ${ }^{6,77}$. Therefore, showing how the spectral irradiance and chromaticity change depending on the specifications of the otoscope or positional relationship between the otoscope and headlight can help doctors determine the correct color tone.

In this study, the spectroscopic performance of an otoscope in an otoscopic examination using headlights was evaluated. The mechanism and specifications of the otoscope and other measuring objects for which the performance is evaluated are presented. A method of measuring spectral irradiance of an otoscope by constructing a measuring device using an existing otoscope and headlights as well as a method for evaluation of spectroscopic performance by the spectral irradiance ratio and chromaticity using the measured spectral irradiance are proposed. The evaluation method was used to evaluate the spectroscopic performance of the otoscope.

\section{Measured object}

The spectroscopic performance of the otoscope was evaluated using a headlight. The mechanism of the otoscope and relationship between the otoscope and headlight are described. Figure 1 shows the mechanism of the otoscope and relationship between the otoscope and headlight. In Figure 1, (a) shows a left-side view, (b) shows a front view, (c) shows a right-side view, and (d) shows a cross-sectional view of the front view. The otoscope has wide and narrow mouths centered on the central axis. The headlight was installed on the wide- mouth side of the otoscope. The light emitted from the focal point on the central axis of the headlight entered the otoscope through the wide mouth. The light that entered the otoscope was either direct light that reached the narrow mouth without being reflected on the surface or light reflected on the surface reaching the narrow mouth. The narrow mouth was illuminated with either direct or reflected light. $l$ is the length of the otoscope in the central axis direction, $r_{\mathrm{W}}$ is the radius of the wide mouth, and $r_{\mathrm{N}}$ is the radius of the narrow mouth. The radii $r_{\mathrm{W}}$ and $r_{\mathrm{N}}$ were used to determine the diameter of the wide mouth $2 r_{\mathrm{W}}$ and diameter of the narrow mouth $2 r_{\mathrm{N}} . d$ is the distance from the focal point of the headlight to the center of the narrow mouth, while $\theta$ is the angle between the central axis of the otoscope and central axis of the headlight.

The hole for the evaluation of the direct light in the otoscope and otoscope were set as the measured objects. Table 1 shows the specifications of the measured object. The measured object was numbered according to the specifications. The measured object number of the hole is set as $\mathrm{H} k$, where $k$ is a natural number, from 1 to 3 . The measured object number of the otoscope is set as $\mathrm{O} m$, where $m$ is a natural number, from 1 to 21 . The holes numbered as $\mathrm{H} 1$ to $\mathrm{H} 3$ were used to evaluate the direct light in the otoscope. The hole did not have a thickness corresponding to the length $l$ of the otoscope. Numbers $\mathrm{O} 1$ to $\mathrm{O} 15$ were purchased otoscopes. The manufacturer names were Daiichi Medical Co. Ltd. and Matsuyoshi \& Co. Ltd. The otoscopes were in the shape of either bell or funnel. The surface conditions were black, chromed matte, or chromed gloss. The length $l$, diameter $2 r_{\mathrm{W}}$, and diameter $2 r_{\mathrm{N}}$ were the values mea- 
Table 1 Specifications of measured objects.

\begin{tabular}{|c|c|c|c|c|c|c|c|}
\hline $\mathrm{H} k, \mathrm{O} m$ & Object type & Manufacturer name & Shape & Surface condition & $l[\mathrm{~mm}]$ & $2 r_{\mathrm{W}}[\mathrm{mm}]$ & $2 r_{\mathrm{N}}[\mathrm{mm}]$ \\
\hline $\mathrm{H} 1$ & Hole & - & - & - & - & - & 3 \\
\hline $\mathrm{H} 2$ & Hole & - & - & - & - & - & 4 \\
\hline H3 & Hole & - & - & - & - & - & 5 \\
\hline $\mathrm{O} 1$ & Otoscope & Daiichi medical & Bell & Black & 34.1 & 21.7 & 3 \\
\hline $\mathrm{O} 2$ & Otoscope & Daiichi medical & Bell & Black & 34.1 & 21.7 & 4 \\
\hline $\mathrm{O} 3$ & Otoscope & Daiichi medical & Bell & Black & 34.1 & 21.7 & 5 \\
\hline $\mathrm{O} 4$ & Otoscope & Daiichi medical & Bell & Chromed matte & 34.1 & 21.9 & 3 \\
\hline O5 & Otoscope & Daiichi medical & Bell & Chromed matte & 34.1 & 21.9 & 4 \\
\hline $\mathrm{O} 6$ & Otoscope & Daiichi medical & Bell & Chromed matte & 34.1 & 21.9 & 5 \\
\hline $\mathrm{O} 7$ & Otoscope & Daiichi medical & Bell & Chromed gloss & 34.1 & 22.1 & 3 \\
\hline O8 & Otoscope & Daiichi medical & Bell & Chromed gloss & 34.1 & 22.1 & 4 \\
\hline O9 & Otoscope & Daiichi medical & Bell & Chromed gloss & 34.1 & 22.1 & 5 \\
\hline $\mathrm{O} 10$ & Otoscope & Matsuyoshi & Bell & Chromed gloss & 35.1 & 20.7 & 3.1 \\
\hline $\mathrm{O} 11$ & Otoscope & Matsuyoshi & Bell & Chromed gloss & 35 & 20.7 & 3.9 \\
\hline $\mathrm{O} 12$ & Otoscope & Matsuyoshi & Bell & Chromed gloss & 35 & 20.7 & 5 \\
\hline $\mathrm{O} 13$ & Otoscope & Matsuyoshi & Funnel & Chromed gloss & 34.8 & 12.4 & 2.9 \\
\hline $\mathrm{O} 14$ & Otoscope & Matsuyoshi & Funnel & Chromed gloss & 34.5 & 13.2 & 4.1 \\
\hline $\mathrm{O} 15$ & Otoscope & Matsuyoshi & Funnel & Chromed gloss & 34.8 & 13.6 & 5.1 \\
\hline $\mathrm{O} 16$ & Otoscope & - & Funnel & Aluminized gloss & 34.8 & 12.4 & 2.9 \\
\hline $\mathrm{O} 17$ & Otoscope & - & Funnel & Aluminized gloss & 34.5 & 13.2 & 4.1 \\
\hline $\mathrm{O} 18$ & Otoscope & - & Funnel & Aluminized gloss & 34.8 & 13.6 & 5.1 \\
\hline O19 & Otoscope & - & Funnel & Aluminized gloss & 34.8 & 12 & 2.9 \\
\hline $\mathrm{O} 20$ & Otoscope & - & Funnel & Aluminized gloss & 34.5 & 15.2 & 4.1 \\
\hline $\mathrm{O} 21$ & Otoscope & - & Funnel & Aluminized gloss & 34.8 & 17.6 & 5.1 \\
\hline
\end{tabular}

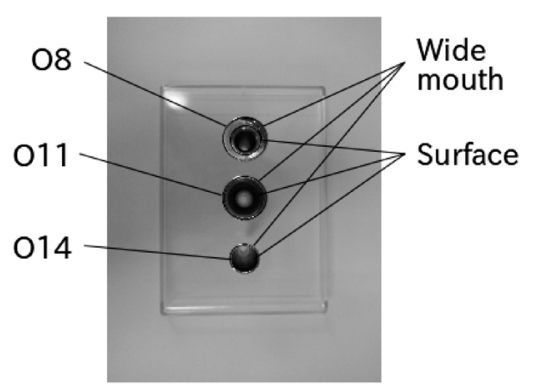

(a) Left side view

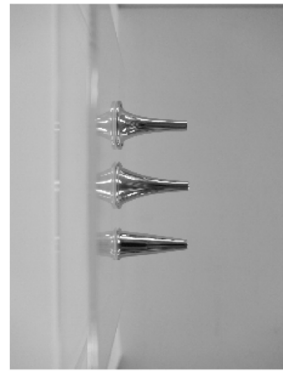

(b) Front view

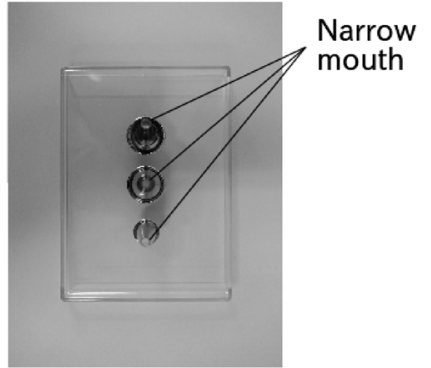

(c) Right side view

Figure 2 Comparison of shape in otoscopes.

sured using a caliper in units of $0.1 \mathrm{~mm}$. The diameters $2 r_{\mathrm{W}}$ and $2 r_{\mathrm{N}}$ were almost identical for numbers $\mathrm{O} 1$ to O9, even under different surface conditions. The length $l$ and diameter $2 r_{\mathrm{W}}$ were different between manufacturers for numbers $\mathrm{O} 7$ to $\mathrm{O} 12$, even when they had the same shape. The length $l$ and diameter $2 r_{\mathrm{W}}$ were different for different shapes for numbers O10 to O15. Numbers $\mathrm{O} 16$ to $\mathrm{O} 18$ were otoscopes with an aluminized glossy surface, to evaluate the difference in surface between $\mathrm{O} 13$ to $\mathrm{O} 15$. The length $l$, diameter $2 r_{\mathrm{W}}$, and diameter $2 r_{\mathrm{N}}$ in $\mathrm{O} 16$ to $\mathrm{O} 18$ were the same as those in $\mathrm{O} 13$ to $\mathrm{O} 15$, respectively. The Viva mirror film by Takahara Corporation was used for the aluminized gloss. Viva mirror film is a film of an aluminum-deposited 0.1-mmthick polyethylene terephthalate sheet with a $0.06-\mathrm{mm}$ thick protective coat. A film was attached to the inner surface in the shape of an otoscope molded from an aluminum alloy. O19 to $\mathrm{O} 21$ indicate otoscopes created by a condensing optimization design by Matsumoto ${ }^{8}$. The length 1 and diameter $2 r_{\mathrm{N}}$ were the same to those for $\mathrm{O} 13$ to $\mathrm{O} 15$, whereas the diameter $2 r_{\mathrm{W}}$ differed. The otoscope creation was the same for $\mathrm{O} 16$ to $\mathrm{O} 18$.

The shapes of the bell- and funnel-type otoscopes shown in Table 1 were compared. Figure 2 compares the otoscope shapes, where (a) shows a left-side view, (b) shows a front view, and (c) shows a right-side view. The image shows the otoscopes O8, O11, and O14. The installation was on a transparent plate so that the surface condition, wide mouth, and narrow mouth of the otoscope could be easily understood. In the figure, (a) shows the wide mouth and surface of the otoscope, (b) shows the outer shape, and (c) shows the narrow 


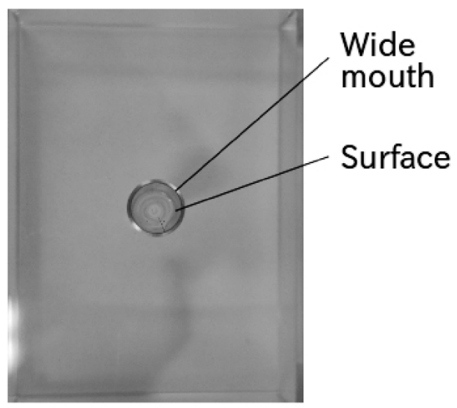

(a) Left side view

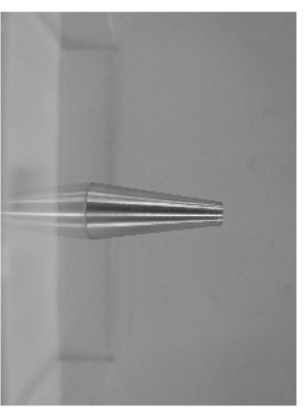

(b) Front view

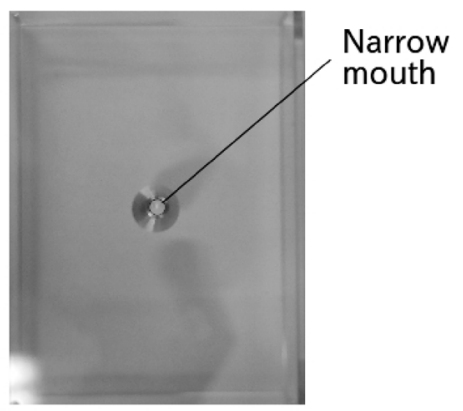

(c) Right side view

Figure 3 Images of created otoscope.

mouth. Comparisons of $\mathrm{O} 8$ and $\mathrm{O} 11$ show that the outer shape was slightly different when the manufacturer was different, even if the shape was the same bell type. Comparisons of $\mathrm{O} 11$ and $\mathrm{O} 14$ show that different shapes resulted in large differences in the wide mouth and outer shape.

The otoscopes $\mathrm{O} 16$ to $\mathrm{O} 21$ in Table 1 were created. Figure 3 shows an image of the created otoscope, where (a) shows a left-side view, (b) shows a front view, and (c) shows a right-side view. The image shows an otoscope O17. It was installed on a transparent plate so that the surface condition, wide mouth, and narrow mouth of the otoscope could be easily understood. In the figure, (a) shows the wide mouth and surface of the otoscope, while (c) shows the narrow mouth. A glossy surface could be observed owing to the aluminized gloss.

\section{Measurement method}

A measuring device using the existing measured object and headlight for the relationship between the otoscope and headlight shown in Figure 1 was built to evaluate the spectroscopic performance of the otoscope. The spectral irradiance of light in the narrow mouth of the measured object was measured using the constructed measuring device. Figure 4 shows an image of the measuring device. The measuring device consisted of a headlight, neutral density filter, measured object, illuminance spectrophotometer, personal computer, and data management software. The Navis LED headlight by AS ONE Corporation was used as the headlight. Navis LED headlights use white-LEDs as a light source and emit light from the focal point of the light source. Navis LED headlights can change the brightness of the LED. However, for the measuring device, they were fixed to the darkest state and used. An ND-0.7 by Fujifilm Corporation was used as the neutral density filter. The ND-0.7 has a transmittance in the range of $15-35 \%$ for wavelengths $\lambda$ in the range of 360 to $760 \mathrm{~nm}$. The ND0.7 was used to reduce the brightness of the light emitted from the Navis LED headlight and adjust it to the measurement range of the illuminance spectrophotometer. The hole and otoscope shown in Table 1 were used

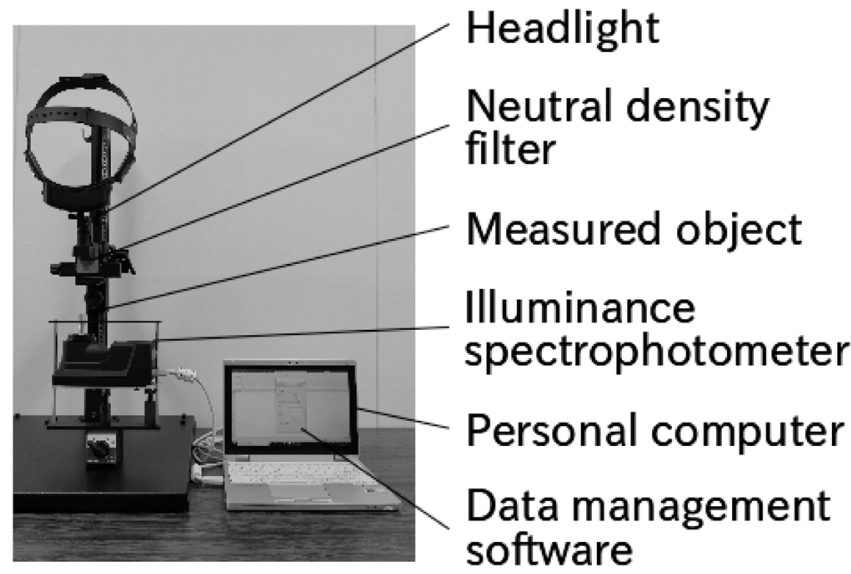

Figure 4 Image of measuring equipment.

Table 2 Measuring conditions.

\begin{tabular}{ccc}
\hline $\mathrm{M} n$ & $d[\mathrm{~mm}]$ & $\theta\left[^{\circ}\right]$ \\
\hline M1 & 132.3 & 0 \\
M2 & 198.3 & 0 \\
M3 & 264.4 & 0 \\
M4 & 132.3 & 5 \\
M5 & 132.3 & 10.1 \\
\hline
\end{tabular}

as the measured objects. A CL-500A manufactured by Konica Minolta Inc. was used as the illuminance spectrophotometer. The CL-500A can measure the spectral irradiance in increments of $1 \mathrm{~nm}$ for the wavelength $\lambda$ in the range of 360 to $780 \mathrm{~nm}$. A CF-RZ5 by Panasonic Corporation was used as the personal computer. A CL-S10w by Konica Minolta Inc. was used for the data management software. The CL-S10w was installed on the CF-RZ5. The CL-500A could be connected to the CF-RZ5 and the measured values could be obtained using the CL-S10w. Navis LED headlights were installed on the wide-mouth side of the otoscope. The distance $d$ and angle $\theta$ were set in the Navis LED headlight by changing the setting position of the focal point. The CL-500A was installed in the narrow mouth of the measured object. The measuring device was installed in a dark room to block light other than that from the Navis LED headlight. The spectral irradiance was measured 
by turning the headlight on and off to remove stray light other than that from the Navis LED headlight and using the difference between those values.

Table 2 shows the measurement conditions. Measurement numbers were assigned for each measurement condition regarding measurements with a measuring device. The measurement numbers were set as $\mathrm{M} n$, where $n$ is a natural number, from 1 to 5 . The distance $d$ and angle $\theta$ were set and measured using the measured objects with numbers $\mathrm{H} k$ and $\mathrm{O} m$. The distance $d$ of $132.3 \mathrm{~mm}$ was set as the distance where the light spreading at $12.8^{\circ}$ from the focal point of the Navis LED headlight corresponds to the diameter $2 r_{\mathrm{W}}$. The value of $132.3 \mathrm{~mm}$ was the distance corresponding to $\mathrm{O} 7$ to 09, which has the largest diameter of $2 r_{\mathrm{W}}$. The values of 198.3 and $264.4 \mathrm{~mm}$ were determined according to the focal length of the head mirror, 170-200 mm (Hinoki) and $200-250 \mathrm{~mm}(\mathrm{Kaga})^{1,2)}$. The angle $\theta$ was determined according to the inclination of the surface from the wide mouth to the narrow mouth in O21. The angle for the surface inclination was $10.1^{\circ}$. Each measuring device was configured based on the measurement conditions shown in Table 2.

\section{Evaluation method}

The spectral irradiances of the measured objects in Table 1 were measured using the measuring device shown in Figure 4 and measuring conditions in Table 2. The distribution of spectral irradiance for each wavelength $\lambda$ could be obtained by the measurements. Additionally, the spectral irradiance of only the reflected light on the surface of the otoscope could be obtained by the measured spectral irradiance. The distribution of the reflected light in the spectral irradiance for each wavelength $\lambda$ could be obtained. The spectral irradiance ratio was used to clearly show the change in spectral irradiance due to the use of the otoscope in the evaluation of the spectroscopic performance. The chromaticity that indicates the color tone was also used.

The spectral irradiance of the reflected light was obtained by subtracting the spectral irradiance in the hole from the spectral irradiance in the otoscope. The spectral irradiance of $i_{\mathrm{H} k, \mathrm{M} n}$ was set for numbers $\mathrm{H} k$ and $\mathrm{M} n$ shown in Tables 1 and 2. The spectral irradiance of $i_{\mathrm{O} m, \mathrm{M} n}$ was set for numbers $\mathrm{O} m$ and $\mathrm{M} n$ shown in Tables 1 and 2 . The spectral irradiance of only the reflected light, $i_{\mathrm{O} m, \mathrm{M} n}-i_{\mathrm{H} k, \mathrm{M} n}$, was determined by subtracting the spectral irradiance $i_{\mathrm{H} k, \mathrm{M} n}$ from the spectral irradiance $i_{\mathrm{O} m, \mathrm{M} n}$. The measurement conditions were fixed to M1 and the measured object number of the hole was fixed to $\mathrm{H} 3$ to compare the spectral irradiance $i_{\mathrm{O} m, \mathrm{M} n}-i_{\mathrm{H} k, \mathrm{M} n}$ of the reflected light only for the surface conditions. The spectral irradiance of the reflected light was $i_{\mathrm{O} m, \mathrm{M} 1}-i_{\mathrm{H} 3, \mathrm{M} 1}$.

The spectral irradiance ratio is the ratio of the spec- tral irradiance in the otoscope to the spectral irradiance in the hole. For example, the spectral irradiance ratio is 1 if there is no change in the spectral irradiance of the otoscope with respect to the spectral irradiance of the hole. The change in the spectral irradiance can be determined regardless of the magnitude of the spectral irradiance. $f_{\mathrm{S}}$ is the spectral irradiance ratio of only the reflected light on the surface of the otoscope. $f_{\mathrm{O}}$ is the spectral irradiance of the entire otoscope that combines direct light and reflected light.

The spectral irradiance ratio $f_{\mathrm{S}}$ was determined. The effect of only reflected light on the surface of the otoscope was evaluated by the spectral irradiance ratio $f_{0}$. The spectral irradiance ratio $f_{0}$ was obtained by dividing the spectral irradiance $i_{\mathrm{O} m, \mathrm{M} n}-i_{\mathrm{H} k, \mathrm{Mn}}$ of only the reflected light by the spectral irradiance $i_{\mathrm{H} k, \mathrm{M} n}$. The spectral irradiance ratio $f_{\mathrm{S}}$ can be expressed as

$$
f_{\mathrm{S}}=\left(i_{\mathrm{Om}, \mathrm{M} n}-i_{\mathrm{H} k, \mathrm{M} n}\right) / i_{\mathrm{H} k, \mathrm{M} n}
$$

For the spectral irradiance ratio $f_{\mathrm{S}}$, the measurement conditions were set as those of M1, while the otoscopes for $\mathrm{O} 3, \mathrm{O} 6, \mathrm{O} 9, \mathrm{O} 12, \mathrm{O} 15, \mathrm{O} 18$, and $\mathrm{O} 21$ were used for the hole of H3. The effects of the differences in the shape, surface, length $l$, and diameter $2 r_{\mathrm{W}}$ on the surface of the otoscope were evaluated for a diameter $2 r_{\mathrm{N}}$ of 5 or $5.1 \mathrm{~mm}$.

The spectral irradiance ratio $f_{\mathrm{O}}$ was obtained. The entire otoscope that combines the reflected light and direct light was evaluated by the spectral irradiance ratio $f_{\mathrm{O}}$. The combined spectral irradiance of the reflected light and direct light is the spectral irradiance $i_{\mathrm{O} m, \mathrm{M} n}$. Furthermore, by dividing it by the spectral irradiance $i_{\mathrm{H} k, \mathrm{M} n}$, we obtain the spectral irradiance ratio $f_{\mathrm{O}}$,

$$
f_{\mathrm{O}}=i_{\mathrm{O} m, \mathrm{M} n} / i_{\mathrm{H} k, \mathrm{M} n}
$$

For the spectral irradiance ratio $f_{\mathrm{O}}$, the effects of differences in the shape, surface, length $l$, and diameter $2 r_{\mathrm{W}}$ on the overall otoscope combining the reflected light and direct light were evaluated for a diameter $2 r_{\mathrm{N}}$ of 5 or $5.1 \mathrm{~mm}$. The effects of differences in the diameter $2 r_{\mathrm{N}}$, distance $d$, and angle $\theta$ on the overall otoscope combining the reflected light and direct light were evaluated. Table 3 shows the correspondence between the numbers $\mathrm{H} k, \mathrm{O} m$, and $\mathrm{M} n$ in Eq. (2).

The chromaticity was obtained by the spectral irradiance of the reflected light as well as by the spectral irradiance of the otoscope using a color matching func-

Table 3 Correspondences of numbers $\mathrm{Hk}, \mathrm{Om}$ and $\mathrm{Mn}$ in Eq. (2).

\begin{tabular}{lll}
\hline $\mathrm{H} k$ & \multicolumn{1}{c}{$\mathrm{O} m$} & \multicolumn{1}{c}{$\mathrm{M} n$} \\
\hline $\mathrm{H} 1$ & $\mathrm{O} 1, \mathrm{O} 4, \mathrm{O} 7, \mathrm{O} 10, \mathrm{O} 13, \mathrm{O} 16, \mathrm{O} 19$ & $\mathrm{M} 1$ \\
$\mathrm{H} 2$ & $\mathrm{O} 2, \mathrm{O} 5, \mathrm{O} 8, \mathrm{O} 11, \mathrm{O} 14, \mathrm{O} 17, \mathrm{O} 20$ & $\mathrm{M} 1$ \\
$\mathrm{H} 3$ & O3, O6, O9, O12, O15, O18, O21 & M1, M2, M3, M4, M5 \\
\hline
\end{tabular}


tion. The chromaticity values $x$ and $y$ of the direct light and reflected light were obtained for the spectral irradiance $i_{\mathrm{O} m, \mathrm{M} 1}-i_{\mathrm{H} 3, \mathrm{M} 1}$ of the reflected light and spectral irradiance $i_{\mathrm{O} m \mathrm{M} n}$. A color matching function for each $\mathrm{nm}$ of the wavelength $\lambda$ in the range of 380 to $780 \mathrm{~nm}$ was obtained.

\section{Performance evaluation}

\subsection{Measured spectral irradiance}

The spectroscopic performance of the otoscope

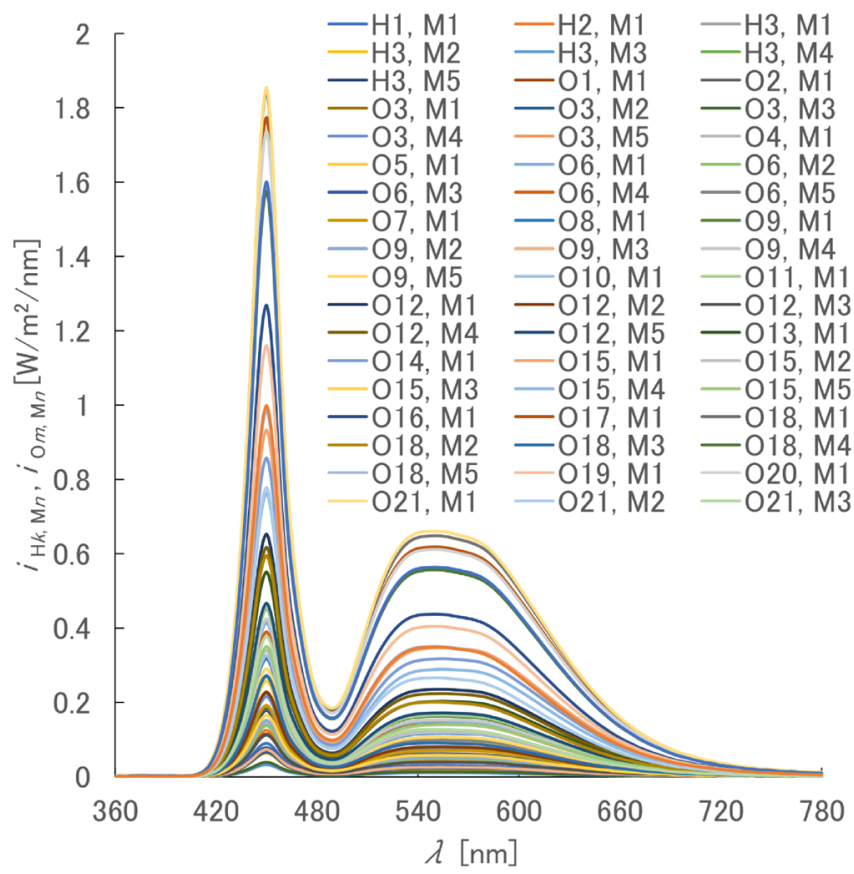

Figure 5 Measured spectral irradiances.

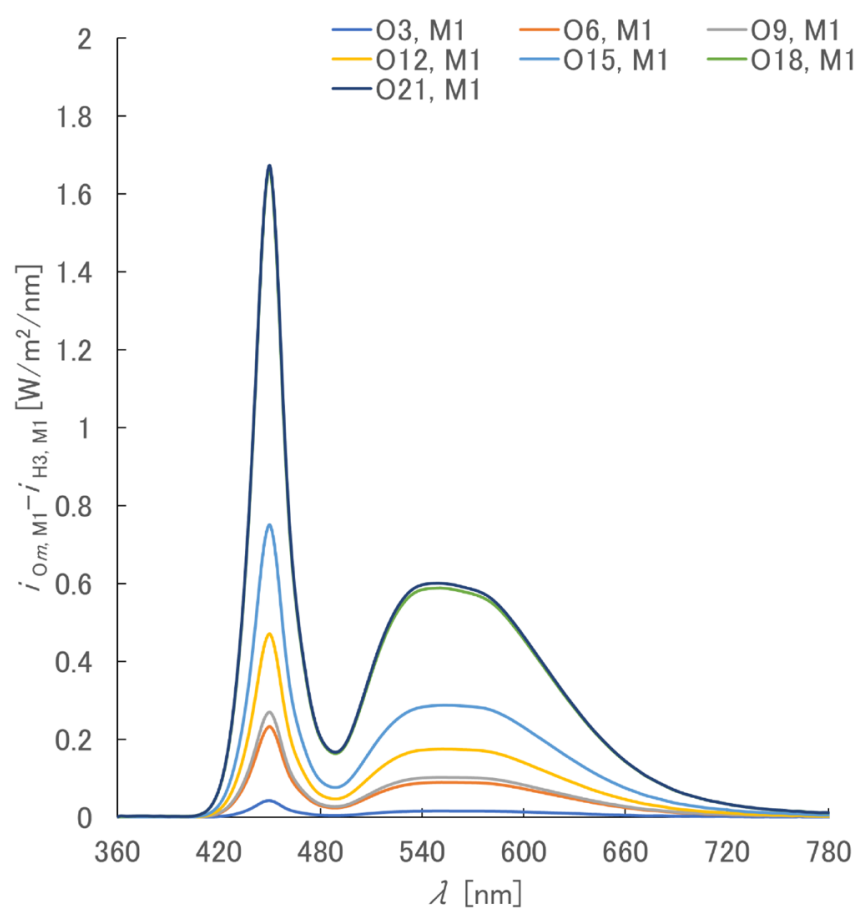

Figure 6 Spectral irradiances of reflected light. was evaluated using the evaluation method. Figure 5 shows the measured spectral irradiance, while Figure 6 shows the spectral irradiance of the reflected light. The distributions of the spectral irradiances $i_{\mathrm{H} k, \mathrm{M} n}$, $i_{\mathrm{O} m, \mathrm{M} n}$, and $i_{\mathrm{O} m, \mathrm{M} 1}-i_{\mathrm{H} 3, \mathrm{M} 1}$ at the wavelength $\lambda$ are shown. Figure 5 shows that the spectral irradiance $i_{\mathrm{O} m, \mathrm{M} n}$ is larger than the spectral irradiance $i_{\mathrm{H} k, \mathrm{M} n}$. Furthermore, the maximum ranges of the wavelength $\lambda$ where the spectral irradiances $i_{\mathrm{H} k, \mathrm{M} n}$ and $i_{\mathrm{O} m, \mathrm{M} n}$ become zero in all distributions were $360-409 \mathrm{~nm}$ and $741-780 \mathrm{~nm}$, respectively. Figure 6 shows that the spectral irradiance $i_{\mathrm{O} m, \mathrm{M} 1}-i_{\mathrm{H} 3, \mathrm{M} 1}$ increased in the order of black, chromed matte, chromed gloss, and aluminized gloss, regarding the different surface conditions. Figures 5 and 6 show that the spectral irradiances $i_{\mathrm{H} k, \mathrm{M} n}, i_{\mathrm{O} m, \mathrm{M} n}$, and $i_{\mathrm{O} m, \mathrm{M} 1}-$ $i_{\mathrm{H} 3 \mathrm{M} 1}$ had peaks at wavelengths $\lambda$ of approximately 450 and $540 \mathrm{~nm}$ for all distributions, because the light source of the white-LED was used for the headlight in the measuring device, similar to the spectral distribution of the white-LED. Therefore, the spectral distribution of the headlight source had a major effect on the distributions of the spectral irradiances $i_{\mathrm{H} k, \mathrm{M} n}, i_{\mathrm{O} m, \mathrm{M} n}$, and $i_{\mathrm{O} m, \mathrm{M} 1}-i_{\mathrm{H} 3, \mathrm{M} 1}$.

\subsection{Spectral irradiance ratio of the reflected light}

Figure 7 shows the spectral irradiance ratio of the reflected light. The distribution of the spectral irradiance ratio $f_{\mathrm{S}}$ at the wavelength $\lambda$ is shown. The spectral irradiance ratio $f_{\mathrm{S}}$ cannot be determined when the spectral irradiance $i_{\mathrm{H} k \mathrm{M} n}$ is zero. Therefore, according to Figure 5 , the range of the wavelength $\lambda$ was set to $410-740 \mathrm{~nm}$, where the spectral irradiance $i_{\mathrm{H} k, \mathrm{M} n}$ is not zero.

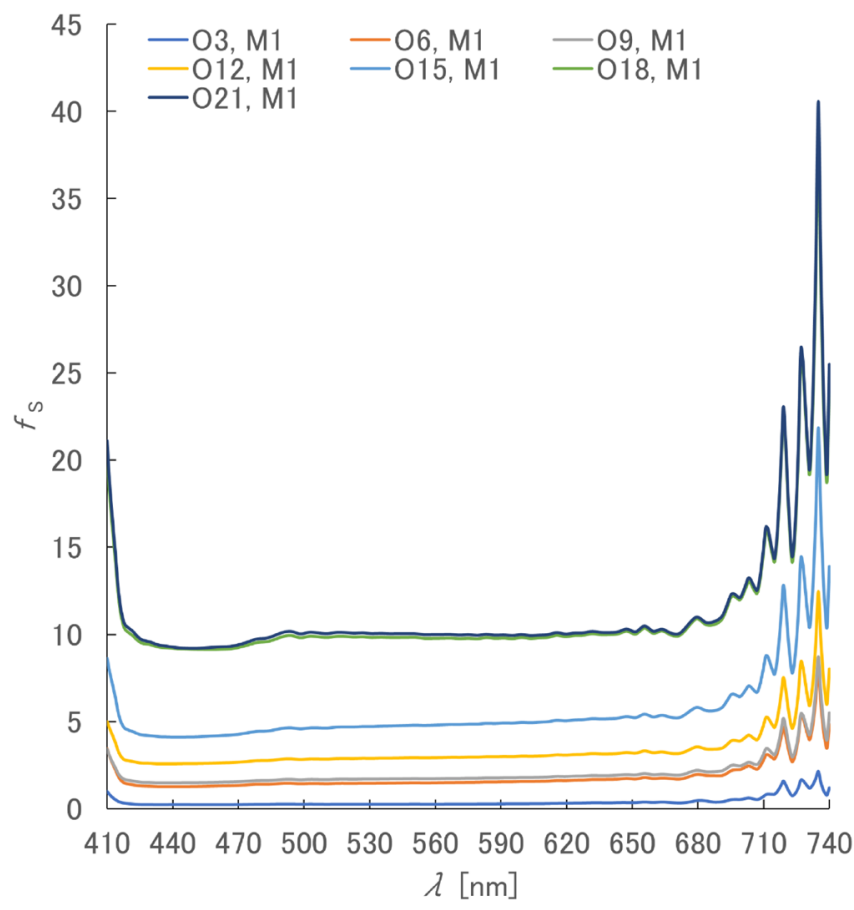

Figure 7 Spectral irradiance ratios of reflected light. 
The spectral irradiance ratio $f_{\mathrm{S}}$ became larger for the funnel type, compared to the bell type, regarding the different shapes. Regarding the different surface conditions, the ratio increased in the order of black, chromed matte, chromed gloss, and aluminized gloss. Regarding the comparison by length $l$ and diameter $2 r_{\mathrm{W}}$, the value became larger with the bell type when the length $l$ was larger and the diameter $2 r_{\mathrm{W}}$ was smaller. The ratio was larger with the funnel type when the diameter $2 r_{\mathrm{W}}$ was larger.

The spectral irradiance ratio $f_{\mathrm{S}}$ largely increased over the wavelength $\lambda$ ranges of $410-420 \mathrm{~nm}$ and $690-740 \mathrm{~nm}$ for all distributions. The rate of increase was larger for the funnel type than for the bell type, regarding the different shapes. Regarding the different surfaces, the value increased in the order of black, chromed matte, chromed gloss, and aluminized gloss. Regarding the comparison by length $l$ and diameter $2 r_{\mathrm{W}}$, the value became larger with the bell type when the diameter $2 r_{\mathrm{W}}$ was larger. The spectral irradiance ratio $f_{\mathrm{S}}$ did not considerably change even with the increases in the wavelength $\lambda$ in the range of $420-690 \mathrm{~nm}$ and when the surface was black. This ratio increased when the surface was chromed matte, chromed gloss, and aluminized gloss. In addition, the ratio increased with the wavelength $\lambda$ in the range of $470-490 \mathrm{~nm}$. The value did not considerably change when the wavelength $\lambda$ was in the range of 490-690 $\mathrm{nm}$.

Table 4 shows the chromaticity of the reflected light. The chromaticity values $x$ and $y$ were larger for the funnel type than for the bell type, regarding the different shapes. Regarding the different surfaces, the values decreased in the order of black, chromed matte, chromed gloss, and aluminized gloss. Regarding the comparison by length $l$ and diameter $2 r_{\mathrm{W}}$, the values became smaller with the bell type when the length $l$ was larger and the diameter $2 r_{\mathrm{W}}$ was smaller. For the funnel type, the values became larger when the diameter $2 r_{\mathrm{W}}$ became larger.

Figure 5 shows the distribution of the spectral irradiance ratio $f_{\mathrm{S}}$, while Table 4 compares the chromaticity values $x$ and $y$. The rate of increase in the spectral irradiance ratio $f_{\mathrm{S}}$ and chromaticity values $x$ and $y$ were compared in the wavelength $\lambda$ ranges of $410-420 \mathrm{~nm}$

Table 4 Chromaticity of reflected light.

\begin{tabular}{llcc}
\hline O $m$ & M $n$ & $x$ & $y$ \\
\hline O3 & M1 & 0.3053 & 0.2982 \\
O6 & M1 & 0.3026 & 0.3002 \\
O9 & M1 & 0.3012 & 0.299 \\
O12 & M1 & 0.2988 & 0.2965 \\
O15 & M1 & 0.3008 & 0.2998 \\
O18 & M1 & 0.2922 & 0.2901 \\
O21 & M1 & 0.2925 & 0.2915 \\
\hline
\end{tabular}

and $690-740 \mathrm{~nm}$. There was a positive correlation with the shape as well as the length $l$ and diameter $2 r_{\mathrm{W}}$ in the case of the funnel type. There was a negative correlation with the surface as well as the length $l$ and diameter $2 r_{\mathrm{W}}$ in the case of the bell type. The rate of increase in the spectral irradiance ratio $f_{\mathrm{S}}$ and chromaticity values $x$ and $y$ were compared in the wavelength $\lambda$ range of $420-690 \mathrm{~nm}$. There was a negative correlation with the surfaces of chromed matte, chromed gloss, and aluminized gloss. Therefore, the spectroscopic performance of the reflected light on the surface of the otoscope was affected by the differences in the shape, surface, length $l$, and diameter $2 r_{\mathrm{W}}$ of the otoscope.

\subsection{Spectral Irradiance Ratio of Direct Light and Reflected Light}

Table 5 shows the correspondence between the numbers $\mathrm{O} m$ and $\mathrm{M} n$ (Figures 8 to 15 and Tables 6 to 13$)$. Figures 8 to 15 show the spectral irradiance ratios of direct light and reflected light. The distribution of the spectral irradiance ratio $f_{\mathrm{O}}$ at the wavelength $\lambda$ is shown. The spectral irradiance ratio $f_{\mathrm{O}}$ cannot be determined when the spectral irradiance $i_{\mathrm{H} k \mathrm{M} n}$ is zero. Therefore, according to the results in Figure 5, the wavelength $\lambda$ range was set to $410-740 \mathrm{~nm}$, where the spectral irradiance ratio $i_{\mathrm{H} k, \mathrm{M} n}$ is not zero. Tables 6 to 13 show the chromaticity values of the direct light and reflected light.

The distribution of the spectral irradiance ratio $f_{\mathrm{O}}$ in Figure 8 was compared to the distribution of the spectral irradiance ratio $f_{\mathrm{S}}$ shown in Figure 6 . The spectral irradiance ratio $f_{\mathrm{O}}$ was larger than the spectral irradiance ratio $f_{\mathrm{S}}$, but there were no changes in their respec-

Table 5 Correspondences of numbers $\mathrm{O} m$ and $\mathrm{Mn}$ in Figure 8 through Figure 15 and Table 6 through Table 13.

\begin{tabular}{|c|c|c|c|}
\hline Figure & Table & $\mathrm{O} m$ & $\mathrm{M} n$ \\
\hline 8 & 6 & O3, O6, O9, O12, O15, O18, O2 & M1 \\
\hline 9 & 7 & $\begin{array}{l}\mathrm{O} 1, \mathrm{O} 2, \mathrm{O} 3 \\
\mathrm{O} 3\end{array}$ & $\begin{array}{l}\text { M1 } \\
\text { M2, M3, M4, M5 }\end{array}$ \\
\hline 10 & 8 & $\begin{array}{l}\mathrm{O} 4, \mathrm{O} 5, \mathrm{O} 6 \\
\mathrm{O} 6\end{array}$ & $\begin{array}{l}\text { M1 } \\
\text { M2, M3, M4, M5 }\end{array}$ \\
\hline 11 & 9 & $\begin{array}{l}\text { O7, O8, } 09 \\
\text { O9 }\end{array}$ & $\begin{array}{l}\text { M1 } \\
\text { M2, M3, M4, M5 }\end{array}$ \\
\hline 12 & 10 & $\begin{array}{l}\mathrm{O} 10, \mathrm{O} 11, \mathrm{O} 12 \\
\mathrm{O} 12\end{array}$ & $\begin{array}{l}\text { M1 } \\
\text { M2, M3, M4, M5 }\end{array}$ \\
\hline 13 & 11 & $\begin{array}{l}\text { O13, O14, O15 } \\
\text { O15 }\end{array}$ & $\begin{array}{l}\text { M1 } \\
\text { M2, M3, M4, M5 }\end{array}$ \\
\hline 14 & 12 & $\begin{array}{l}\mathrm{O} 16, \mathrm{O} 17, \mathrm{O} 18 \\
\mathrm{O} 18\end{array}$ & $\begin{array}{l}\text { M1 } \\
\text { M2, M3, M4, M5 }\end{array}$ \\
\hline 15 & 13 & $\begin{array}{l}\text { O19, O20, O21 } \\
\text { O21 }\end{array}$ & $\begin{array}{l}\text { M1 } \\
\text { M2, M3, M4, M5 }\end{array}$ \\
\hline
\end{tabular}




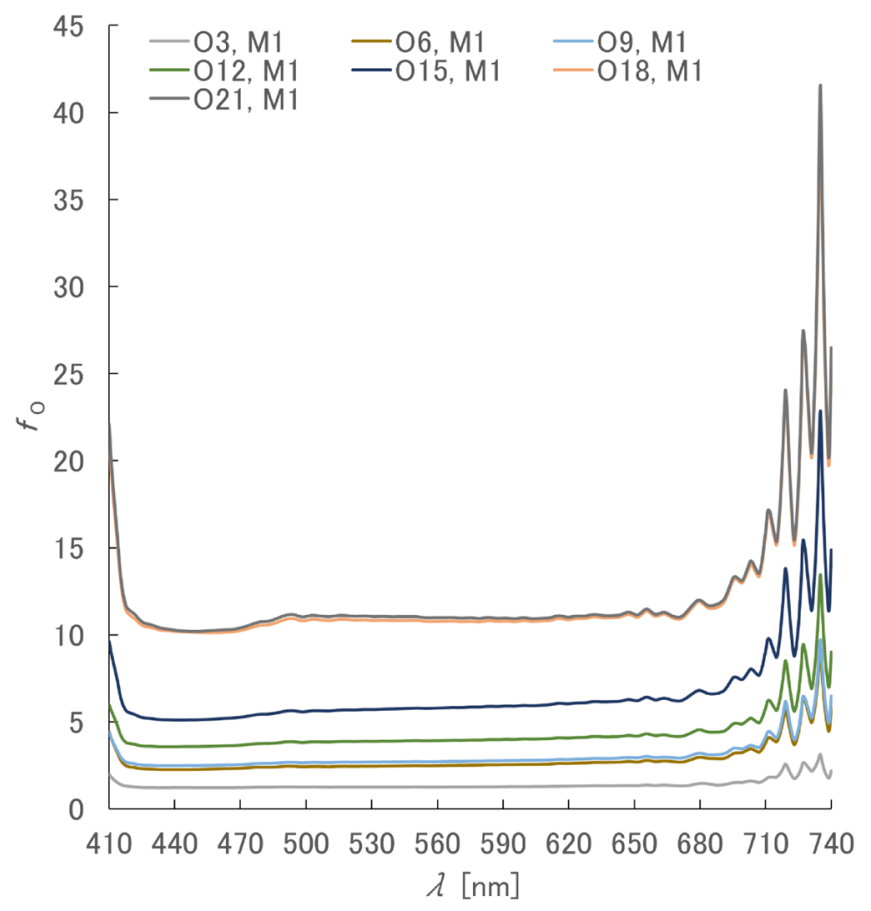

Figure 8 Spectral irradiance ratios of direct and reflected lights in cases of numbers $\mathrm{O} 3$ and $\mathrm{M} 1, \mathrm{O} 6$ and $\mathrm{M} 1$, $\mathrm{O} 9$ and $\mathrm{M} 1, \mathrm{O} 12$ and $\mathrm{M} 1, \mathrm{O} 15$ and $\mathrm{M} 1, \mathrm{O} 18$ and $\mathrm{M} 1$, and $\mathrm{O} 21$ and $\mathrm{M} 1$.

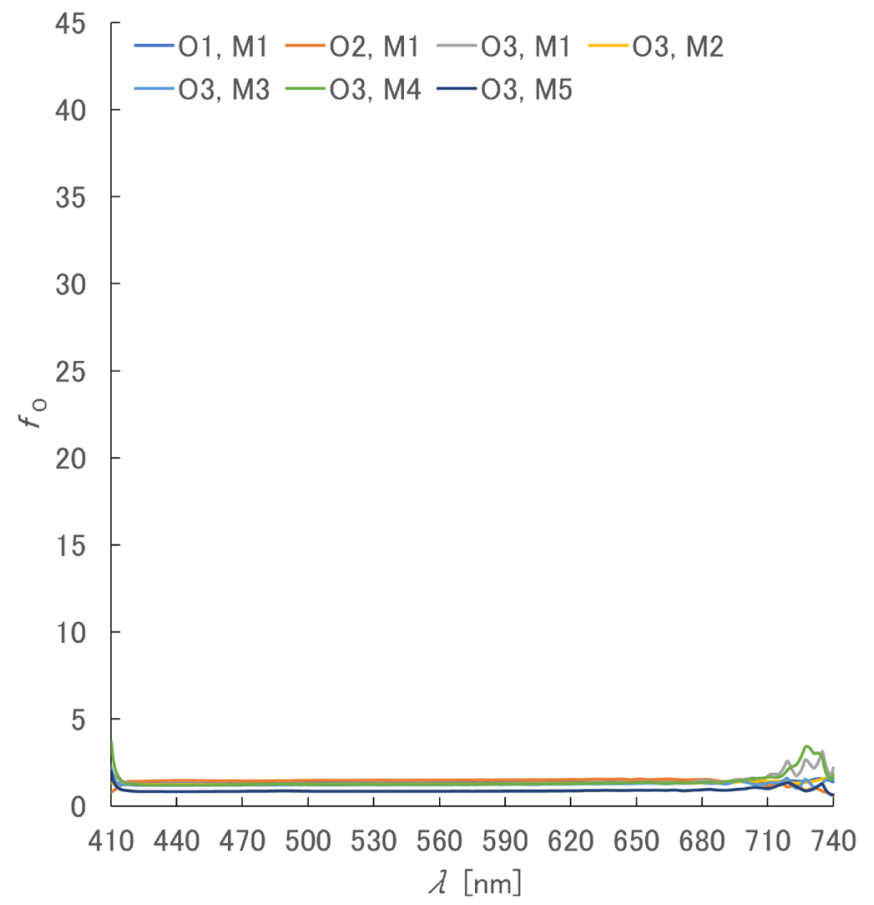

Figure 9 Spectral irradiance ratios of direct and reflected lights in cases of numbers $\mathrm{O} 1$ and $\mathrm{M} 1, \mathrm{O} 2$ and $\mathrm{M} 1$, $\mathrm{O} 3$ and $\mathrm{M} 1, \mathrm{O} 3$ and $\mathrm{M} 2, \mathrm{O} 3$ and $\mathrm{M} 3, \mathrm{O} 3$ and M4, and $\mathrm{O} 3$ and $\mathrm{M} 5$.

tive distributions. According to the results shown in Table 6 , the chromaticity values $x$ and $y$ were larger for the funnel type than for the bell type, regarding the comparison by shapes. Regarding the comparison by

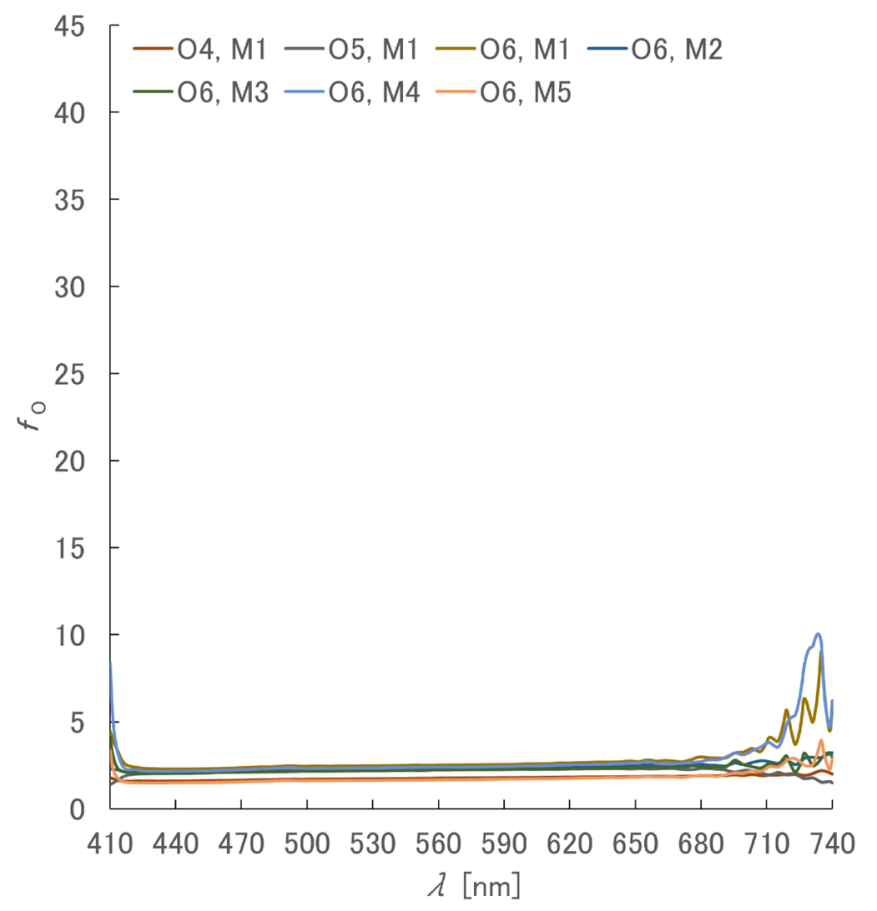

Figure 10 Spectral irradiance ratios of direct and reflected lights in cases of numbers $\mathrm{O} 4$ and $\mathrm{M} 1, \mathrm{O} 5$ and $\mathrm{M} 1$, $\mathrm{O} 6$ and $\mathrm{M} 1, \mathrm{O} 6$ and $\mathrm{M} 2, \mathrm{O} 6$ and $\mathrm{M} 3, \mathrm{O} 6$ and $\mathrm{M} 4$, and $\mathrm{O} 6$ and M5.

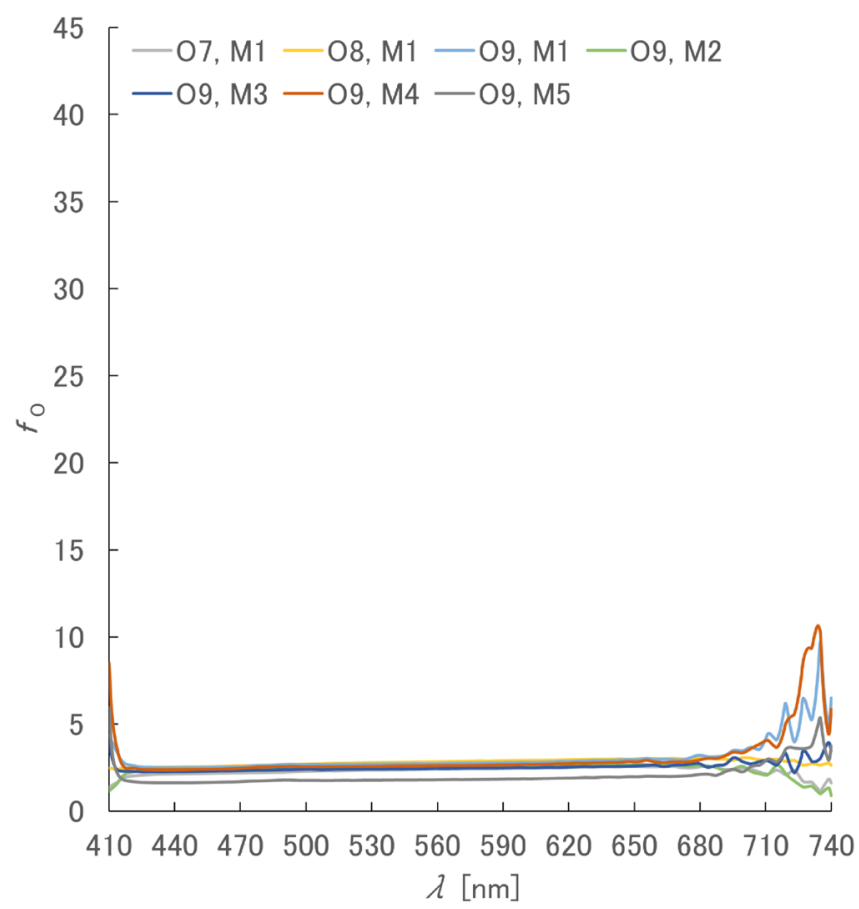

Figure 11 Spectral irradiance ratios of direct and reflected lights in cases of numbers $\mathrm{O} 7$ and $\mathrm{M} 1, \mathrm{O} 8$ and $\mathrm{M} 1$, $\mathrm{O} 9$ and M1, O9 and M2, O9 and M3, O9 and M4, and $\mathrm{O} 9$ and M5.

surface, the values decreased in the order of chromed matte, chromed gloss, aluminized gloss, and black. Regarding the comparison by length $l$ and diameter $2 r_{\mathrm{W}}$, the values did not considerably change for the bell type. 


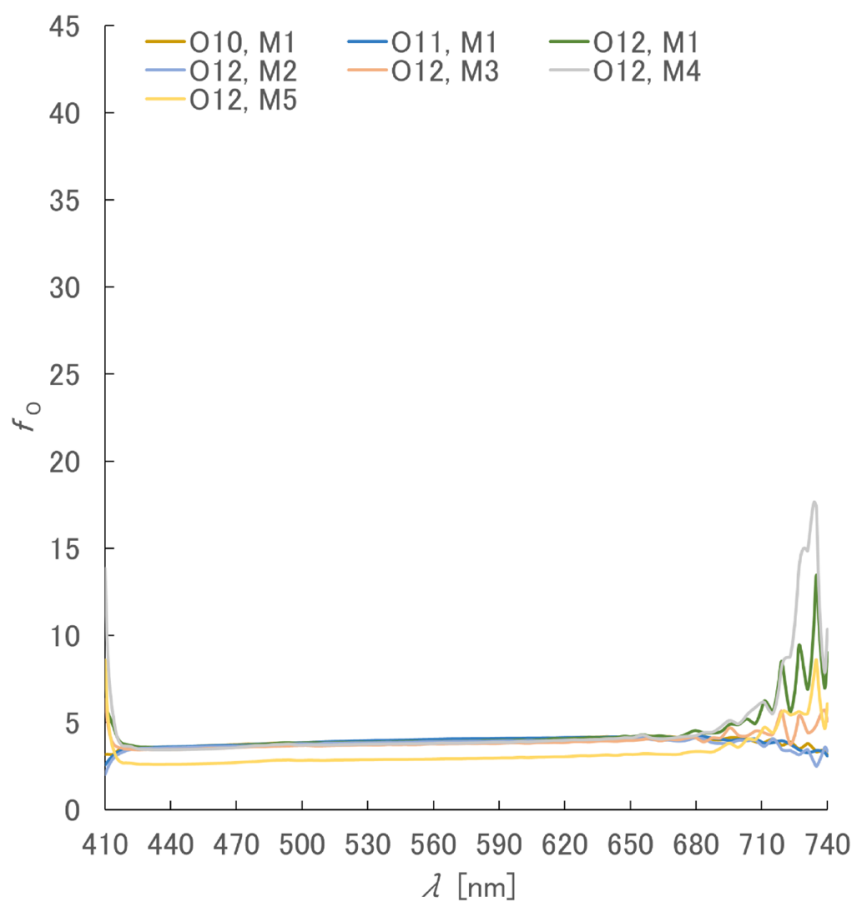

Figure 12 Spectral irradiance ratios of direct and reflected lights in cases of numbers $\mathrm{O} 10$ and $\mathrm{M} 1, \mathrm{O} 11$ and $\mathrm{M} 1, \mathrm{O} 12$ and $\mathrm{M} 1, \mathrm{O} 12$ and $\mathrm{M} 2, \mathrm{O} 12$ and $\mathrm{M} 3, \mathrm{O} 12$ and $\mathrm{M} 4$, and $\mathrm{O} 12$ and $\mathrm{M} 5$.

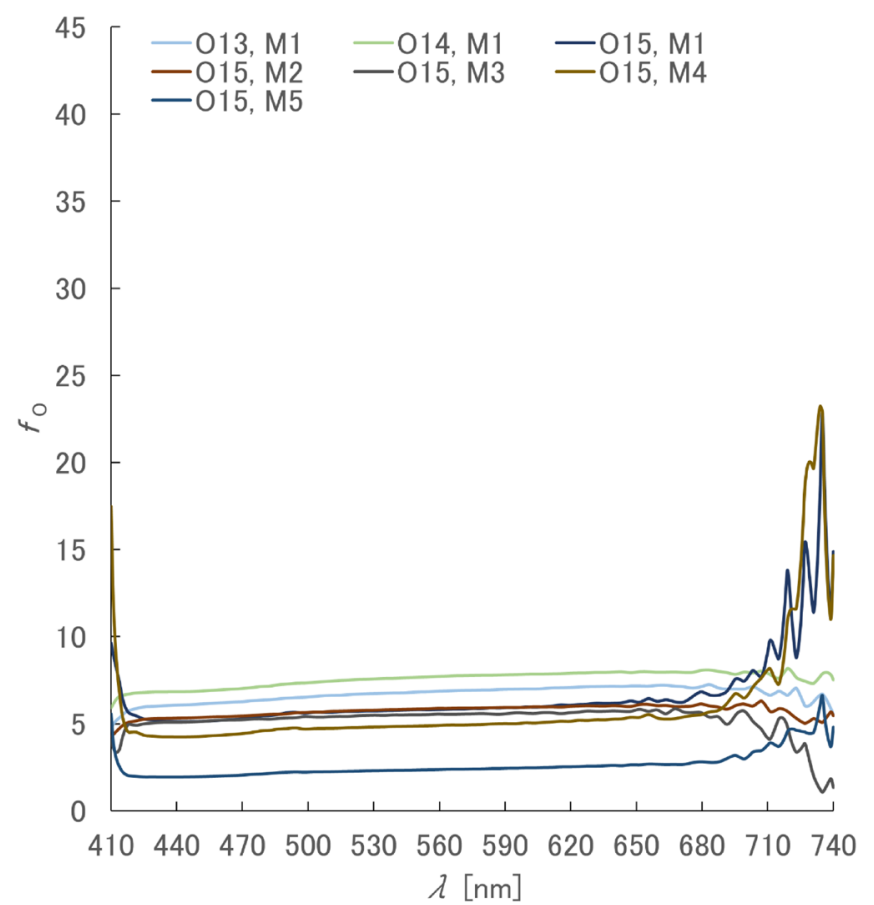

Figure 13 Spectral irradiance ratios of direct and reflected lights in cases of numbers 013 and $\mathrm{M} 1, \mathrm{O} 14$ and $\mathrm{M} 1, \mathrm{O} 15$ and $\mathrm{M} 1, \mathrm{O} 15$ and $\mathrm{M} 2, \mathrm{O} 15$ and $\mathrm{M} 3, \mathrm{O} 15$ and $\mathrm{M} 4$, and $\mathrm{O} 15$ and $\mathrm{M} 5$.

For the funnel type, the values became larger when the diameter $2 r_{\mathrm{W}}$ was larger. The chromaticity values $x$ and $y$ of the reflected light shown in Table 4 were compared

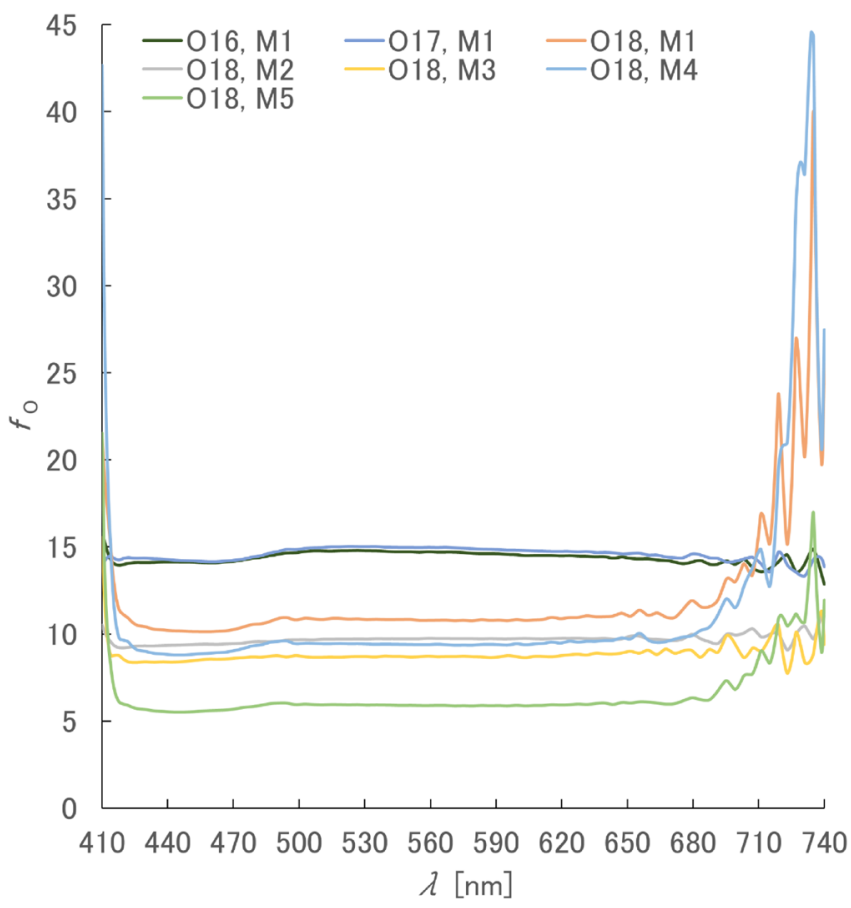

Figure 14 Spectral irradiance ratios of direct and reflected lights in cases of numbers $\mathrm{O} 16$ and $\mathrm{M} 1, \mathrm{O} 17$ and $\mathrm{M} 1, \mathrm{O} 18$ and $\mathrm{M} 1, \mathrm{O} 18$ and $\mathrm{M} 2, \mathrm{O} 18$ and $\mathrm{M} 3, \mathrm{O} 18$ and $\mathrm{M} 4$, and $\mathrm{O} 18$ and $\mathrm{M} 5$.

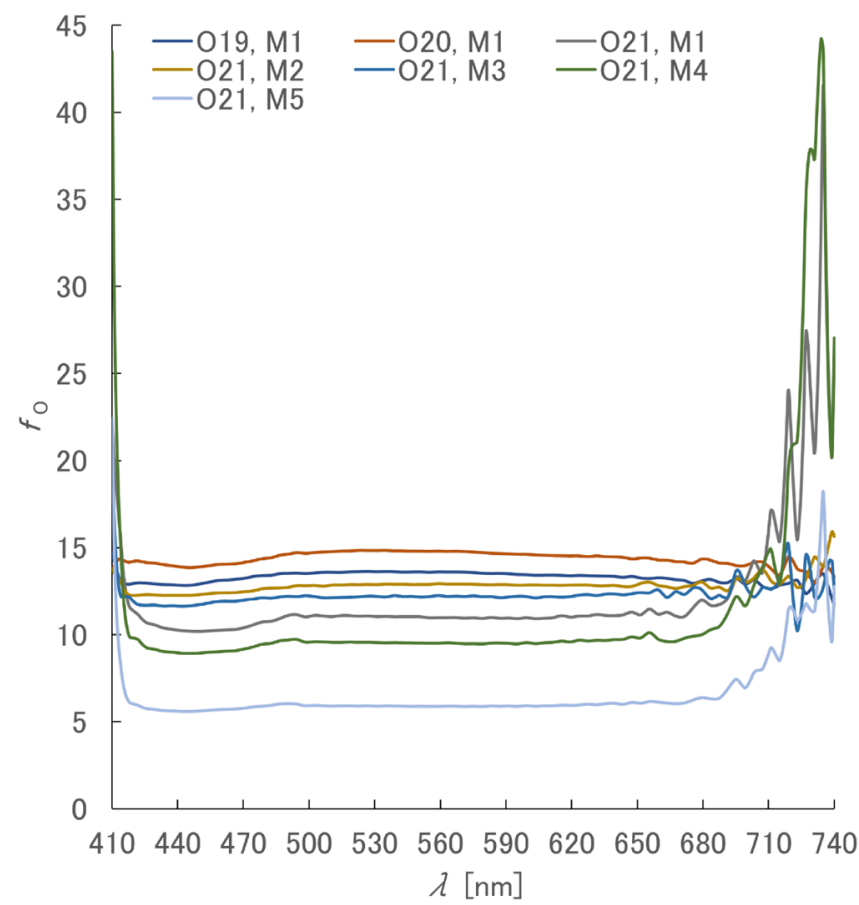

Figure 15 Spectral irradiance ratios of direct and reflected lights in cases of numbers $\mathrm{O} 19$ and M1, O20 and $\mathrm{M} 1, \mathrm{O} 21$ and M1, O21 and M2, O21 and M3, O21 and M4, and $\mathrm{O} 21$ and M5.

to those of the direct light and reflected light shown in Table 6 . The chromaticity values $x$ and $y$ were smaller for those of the direct light and reflected light than 
Table 6 Chromaticity of direct and reflected lights in cases of numbers $\mathrm{O} 3$ and $\mathrm{M} 1, \mathrm{O} 6$ and $\mathrm{M} 1, \mathrm{O} 9$ and $\mathrm{M} 1, \mathrm{O} 12$ and $\mathrm{M} 1, \mathrm{O} 15$ and $\mathrm{M} 1, \mathrm{O} 18$ and $\mathrm{M} 1$, and $\mathrm{O} 21$ and $\mathrm{M} 1$.

\begin{tabular}{llll}
\hline O $m$ & M $n$ & \multicolumn{1}{c}{$x$} & \multicolumn{1}{c}{$y$} \\
\hline O3 & M1 & 0.2912 & 0.2849 \\
O6 & M1 & 0.2964 & 0.2924 \\
O9 & M1 & 0.296 & 0.2923 \\
O12 & M1 & 0.2958 & 0.2925 \\
O15 & M1 & 0.2984 & 0.2964 \\
O18 & M1 & 0.2917 & 0.2893 \\
O21 & M1 & 0.2921 & 0.2906 \\
\hline
\end{tabular}

Table 7 Chromaticity of direct and reflected lights in cases of numbers $\mathrm{O} 1$ and $\mathrm{M} 1, \mathrm{O} 2$ and $\mathrm{M} 1, \mathrm{O} 3$ and $\mathrm{M} 1, \mathrm{O} 3$ and $\mathrm{M} 2, \mathrm{O} 3$ and $\mathrm{M} 3, \mathrm{O} 3$ and $\mathrm{M} 4$, and $\mathrm{O} 3$ and $\mathrm{M} 5$.

\begin{tabular}{cccc}
\hline Om & Mn & $x$ & $y$ \\
\hline O1 & M1 & 0.2922 & 0.2857 \\
O2 & M1 & 0.2913 & 0.2849 \\
O3 & M1 & 0.2912 & 0.2849 \\
O3 & M2 & 0.2901 & 0.2833 \\
O3 & M3 & 0.2896 & 0.2826 \\
O3 & M4 & 0.2914 & 0.2858 \\
O3 & M5 & 0.2904 & 0.2848 \\
\hline
\end{tabular}

Table 8 Chromaticity of direct and reflected lights in cases of numbers $\mathrm{O} 4$ and $\mathrm{M} 1, \mathrm{O} 5$ and $\mathrm{M} 1, \mathrm{O} 6$ and $\mathrm{M} 1, \mathrm{O} 6$ and M2, $\mathrm{O} 6$ and M3, O6 and M4, and $\mathrm{O} 6$ and M5.

\begin{tabular}{cccl}
\hline O $m$ & $\mathrm{M} n$ & $x$ & \multicolumn{1}{c}{$y$} \\
\hline O4 & M1 & 0.2967 & 0.2921 \\
O5 & M1 & 0.2956 & 0.2916 \\
O6 & M1 & 0.2964 & 0.2924 \\
O6 & M2 & 0.2946 & 0.2897 \\
O6 & M3 & 0.2935 & 0.2882 \\
O6 & M4 & 0.2968 & 0.293 \\
O6 & M5 & 0.2976 & 0.2943 \\
\hline
\end{tabular}

Table 9 Chromaticity of direct and reflected lights in cases of numbers $\mathrm{O} 7$ and $\mathrm{M} 1, \mathrm{O} 8$ and $\mathrm{M} 1, \mathrm{O} 9$ and $\mathrm{M} 1, \mathrm{O} 9$ and $\mathrm{M} 2, \mathrm{O} 9$ and $\mathrm{M} 3, \mathrm{O} 9$ and $\mathrm{M} 4$, and $\mathrm{O} 9$ and M5.

\begin{tabular}{clll}
\hline O $m$ & M $n$ & \multicolumn{1}{c}{$x$} & $y$ \\
\hline O7 & M1 & 0.2991 & 0.2956 \\
O8 & M1 & 0.2988 & 0.2952 \\
O9 & M1 & 0.296 & 0.2923 \\
O9 & M2 & 0.2934 & 0.2887 \\
O9 & M3 & 0.2931 & 0.2879 \\
O9 & M4 & 0.2961 & 0.2926 \\
O9 & M5 & 0.2972 & 0.2941 \\
\hline
\end{tabular}

Table 10 Chromaticity of direct and reflected lights in cases of numbers $\mathrm{O} 10$ and $\mathrm{M} 1, \mathrm{O} 11$ and $\mathrm{M} 1, \mathrm{O} 12$ and $\mathrm{M} 1$, $\mathrm{O} 12$ and $\mathrm{M} 2, \mathrm{O} 12$ and $\mathrm{M} 3, \mathrm{O} 12$ and $\mathrm{M} 4$, and $\mathrm{O} 12$ and M5.

\begin{tabular}{llll}
\hline $\mathrm{O} m$ & $\mathrm{M} n$ & \multicolumn{1}{c}{$\boldsymbol{x}$} & \multicolumn{1}{c}{$\boldsymbol{y}$} \\
\hline $\mathrm{O} 10$ & $\mathrm{M} 1$ & 0.2971 & 0.2937 \\
$\mathrm{O} 11$ & $\mathrm{M} 1$ & 0.2974 & 0.2942 \\
$\mathrm{O} 12$ & $\mathrm{M} 1$ & 0.2958 & 0.2925 \\
$\mathrm{O} 12$ & $\mathrm{M} 2$ & 0.294 & 0.2897 \\
$\mathrm{O} 12$ & $\mathrm{M} 3$ & 0.2933 & 0.2886 \\
$\mathrm{O} 12$ & $\mathrm{M} 4$ & 0.2964 & 0.2933 \\
$\mathrm{O} 12$ & $\mathrm{M} 5$ & 0.2977 & 0.295 \\
\hline
\end{tabular}

Table 11 Chromaticity of direct and reflected lights in cases of numbers $\mathrm{O} 13$ and $\mathrm{M} 1, \mathrm{O} 14$ and $\mathrm{M} 1, \mathrm{O} 15$ and $\mathrm{M} 1$, $\mathrm{O} 15$ and $\mathrm{M} 2, \mathrm{O} 15$ and $\mathrm{M} 3, \mathrm{O} 15$ and M4, and $\mathrm{O} 15$ and M5.

\begin{tabular}{cccc}
\hline Om & Mn & \multicolumn{1}{c}{$x$} & $y$ \\
\hline O13 & M1 & 0.2984 & 0.2956 \\
O14 & M1 & 0.2982 & 0.2957 \\
O15 & M1 & 0.2984 & 0.2964 \\
O15 & M2 & 0.2946 & 0.2909 \\
O15 & M3 & 0.2927 & 0.2884 \\
O15 & M4 & 0.2998 & 0.2985 \\
O15 & M5 & 0.305 & 0.305 \\
\hline
\end{tabular}

Table 12 Chromaticity of direct and reflected lights in cases of numbers $\mathrm{O} 16$ and $\mathrm{M} 1, \mathrm{O} 17$ and $\mathrm{M} 1, \mathrm{O} 18$ and $\mathrm{M} 1$, $\mathrm{O} 18$ and $\mathrm{M} 2, \mathrm{O} 18$ and $\mathrm{M} 3, \mathrm{O} 18$ and $\mathrm{M} 4$, and $\mathrm{O} 18$ and M5.

\begin{tabular}{cccc}
\hline Om & M $n$ & $x$ & $y$ \\
\hline O16 & M1 & 0.2902 & 0.2872 \\
O17 & M1 & 0.2911 & 0.2884 \\
O18 & M1 & 0.2917 & 0.2893 \\
O18 & M2 & 0.2893 & 0.2842 \\
O18 & M3 & 0.2882 & 0.2826 \\
O18 & M4 & 0.2918 & 0.2896 \\
O18 & M5 & 0.2917 & 0.2902 \\
\hline
\end{tabular}

Table 13 Chromaticity of direct and reflected lights in cases of numbers $\mathrm{O} 19$ and $\mathrm{M} 1, \mathrm{O} 20$ and $\mathrm{M} 1, \mathrm{O} 21$ and $\mathrm{M} 1$, $\mathrm{O} 21$ and $\mathrm{M} 2, \mathrm{O} 21$ and $\mathrm{M} 3, \mathrm{O} 21$ and M4, and $\mathrm{O} 21$ and M5.

\begin{tabular}{cccc}
\hline O $m$ & M $n$ & \multicolumn{1}{c}{$x$} & \multicolumn{1}{c}{$y$} \\
\hline O19 & M1 & 0.2907 & 0.288 \\
O20 & M1 & 0.2913 & 0.2892 \\
O21 & M1 & 0.2921 & 0.2906 \\
O21 & M2 & 0.2896 & 0.2855 \\
O21 & M3 & 0.2886 & 0.2836 \\
O21 & M4 & 0.2915 & 0.2893 \\
O21 & M5 & 0.291 & 0.288 \\
\hline
\end{tabular}


those of the reflected light. Furthermore, there was a positive correlation for the shape and surface as well as the length $l$ and diameter $2 r_{\mathrm{W}}$ for the funnel type. Therefore, the spectroscopic performance of the overall otoscope, which combined the direct light and reflected light, was affected by differences in the shape, surface, length $l$, and diameter $2 r_{\mathrm{W}}$ of the otoscope. However, this was different from the spectroscopic performance of the reflected light on the surface of the otoscope.

According to the results shown in Figures 9 to 15, there were differences in the spectral irradiance ratio $f_{\mathrm{O}}$ due to differences in the diameter $2 r_{\mathrm{N}}$, distance $d$, and angle $\theta$. According to the comparison of Figures 9 to 15 , the generated difference became larger for the funnel type than for the bell type, regarding the comparison of shapes. Regarding the comparison of surfaces, the value increased in the order of black, chromed matte, chromed gloss, and aluminized gloss. Regarding the comparison by length $l$ and diameter $2 r_{\mathrm{W}}$, the value increased for the bell type when the length $l$ was larger and the diameter $2 r_{\mathrm{W}}$ was smaller. The value became larger for the bell type when the diameter $2 r_{\mathrm{W}}$ was larger.

Regarding the distribution, the spectral irradiance ratio $f_{\mathrm{O}}$ increased significantly in the wavelength $\lambda$ ranges of $410-420 \mathrm{~nm}$ and $690-740 \mathrm{~nm}$ when the diameter $2 r_{\mathrm{N}}$ was large. The value largely decreased at smaller diameter $2 r_{\mathrm{N}}$ and distance $d$ when the surface was chromed matte or chromed gloss. The value largely fluctuated at smaller diameter $2 r_{\mathrm{N}}$ and distance $d$ when the surface was aluminized gloss. The spectral irradiance ratio $f_{\mathrm{O}}$ did not considerably change even with the increase in the wavelength $\lambda$ in the range of $420-690 \mathrm{~nm}$ when the surface was black. The value increased when the surface was chromed matte or chromed gloss. The rate of increase did not considerably change due to differences in the diameter $2 r_{\mathrm{N}}$, distance $d$, and angle $\theta$. The value increased in the wavelength $\lambda$ range of $470-490 \mathrm{~nm}$ when the surface was aluminized gloss. The rate of increase was higher when the diameter $2 r_{\mathrm{N}}$ was larger.

According to the results in Tables 7 to 13 , there were differences in the chromaticity values $x$ and $y$ according to the differences in the diameter $2 r_{\mathrm{N}}$, distance $d$, and angle $\theta$. Regarding the comparison with the diameter $2 r_{\mathrm{N}}$, the chromaticity values $x$ and $y$ varied more due to differences in $2 r_{\mathrm{N}}$ according to the results in Tables 7, 8, 10, and 11. According to the results in Table 9, the values were smaller when the diameter $2 r_{\mathrm{N}}$ was larger. According to the results in Tables 12 and 13, the values were larger when the diameter $2 r_{\mathrm{N}}$ was larger. Regarding the comparison with the distance $d$, according to the results in Tables 7 and 13, the values were smaller when the distance $d$ was larger. Regarding the comparison with the angle $\theta$, according to the results in Tables 7,8 , and 12 , the values varied according to the differences in angle $\theta$. According to the results in Table 13 , the values were smaller when the angle $\theta$ was larger. Therefore, the otoscopes that correlated with the chromaticity values $x$ and $y$ without variations in the diameter $2 r_{\mathrm{N}}$, distance $d$, and angle $\theta$ were $\mathrm{O} 7$ to $\mathrm{O} 9$ and $\mathrm{O} 19$ to $\mathrm{O} 21$. O7 to $\mathrm{O} 9$ were otoscopes with a bell shape, chromed glossy surface, small length $l$, and large diameter $2 r_{\mathrm{W}}$. $\mathrm{O} 19$ to $\mathrm{O} 21$ were otoscopes with a funnel shape, aluminized glossy surface, and large diameter $2 r_{\mathrm{W}}$ designed for focusing optimization. The correlation between the chromaticity values $x$ and $y$, diameter $2 r_{\mathrm{N}}$, distance $d$, and angle $\theta$ could be determined using these otoscopes. These correlations help doctors determine the accurate color tone.

The distributions of the spectral irradiance ratio $f_{\mathrm{O}}$ in Figures 9 to 13 were compared with the chromaticity values $x$ and $y$ shown in Tables 7 to 13. The fluctuations in the spectral irradiance ratio $f_{\mathrm{S}}$ in the wavelength $\lambda$ ranges of $410-420 \mathrm{~nm}$ and $690-740 \mathrm{~nm}$ were compared with the chromaticity values $x$ and $y$. There was a positive correlation for the diameter $2 r_{\mathrm{N}}$. There was a negative correlation for the angle $\theta$ when the surface was chromed matte or chromed gloss. The increase in the spectral irradiance ratio $f_{\mathrm{S}}$ in the wavelength $\lambda$ range of $420-690 \mathrm{~nm}$ was compared with the chromaticity values $x$ and $y$. There was a positive correlation for the angle $\theta$ when the surface was chromed matte or chromed gloss. There was a positive correlation for the diameter $2 r_{\mathrm{N}}$ when the surface was aluminized gloss. Therefore, the spectroscopic performance of the overall otoscope, which combined reflected light and direct light, was affected by differences in the otoscope diameter $2 r_{\mathrm{N}}$, distance $d$, and angle $\theta$.

\section{Conclusion}

In this study, the spectroscopic performance of the otoscope was evaluated in the otoscopic examination using a headlight. The obtained results can be summarized as follows.

1. The mechanism and specifications of the measured object such as the otoscope for evaluation of the spectroscopic performance were described. A method for configuring a measuring device that used an existing otoscope and headlight and measuring the spectral irradiance of the otoscope was presented. A method for evaluating the spectroscopic performance by the spectral irradiance ratio and chromaticity using the measured spectral irradiance was proposed.

2. The spectral irradiance of the otoscope was measured using the measurement method. The distribution of the spectral irradiance in the otoscope was largely affected by the spectral distribution in the headlight source.

3. The spectroscopic performance of the otoscope 
was evaluated using the evaluation method. The spectroscopic performance of the reflected light in the surface of the otoscope was affected by differences in the shape, surface, length, and wide-mouth diameter of the otoscope. The spectroscopic performance of the overall otoscope combining direct light and reflected light was affected by differences in the surface, length, and wide-mouth diameter. However, this differed from the spectroscopic performance of the reflected light in the surface of the otoscope. Furthermore, differences in the narrow-mouth diameter in the otoscope as well as the distance and angle between the otoscope and headlight were influencing factors.

4. The correlation between the chromaticity, narrowmouth diameter, and distance and angle between the headlight and otoscope could be determined using an otoscope with a bell shape, chromed glossy surface, small length, and large wide-mouth diameter or otoscope with a funnel shape, aluminized glossy surface, and large wide-mouth diameter for focusing optimization. These correlations help doctors determine the exact color tone.

\section{References}

(1) Hinoki, M.: Modern oto-rhino-laryngology, Kane- hara, pp.159-167 (1983).

(2) Kaga, K.: Modern oto-rhino-laryngology, Nanzando, pp.63-64 (2013).

(3) Moriyama, H.: Middle ear. outer ear, Medicalview, p.26 (2000).

(4) Zusho, H.: Headlight using a fiber light source, Oto-Rhino-Laryngology Tokyo, 29-5, pp. 583-586 (1986).

(5) Otsuka, K., Nonaka, M. and Watanabe, S.: Success otolaryngology, Kanehara, p. 23 (2017).

(6) Goto, F. and Yabe, H.: Customized catoptric head mirror with white LED and battery replacement, Oto-Rhino-Laryngology Tokyo, 49-3, pp. 142-144 (2006).

(7) Syouji, K. and Kojima, T.: Head Mirror replacement, Practica Oto-Rhino-Laryngologica, 98-9, pp. 682-683 (2005).

(8) Matsumoto, M.: Performance evaluation and optimization of design of light focus in otoscope during otoscopic examination by headlight, Journal of Science and Technology in Lighting, 44-0, pp. 34-44 (2021).

This paper is translated from the article of the Journal of the Illuminating Engineering Institute of Japan, Vol. 106, 2022 (in Japanese). 